\title{
Prämienentwicklung bereitet weniger Menschen Sorge
}

\author{
Jürg Schlup \\ Dr. med., Präsident der FMH
}

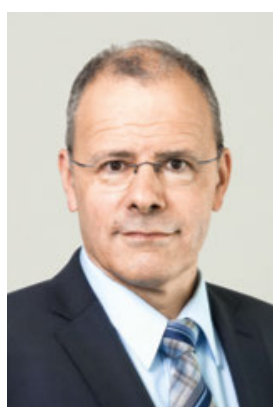

«Prämien bringen fast jede zweite Familie ans Limit» titelte Mitte August 20 Minuten in der gesamten Deutschschweiz und im Tessin und zitierte damit den Vergleichsdienst Comparis. Viele Leser und Leserinnen dürften schockiert gewesen sein, zumal ihnen die entscheidende Information zu den verwendeten Daten vorenthalten wurde. Diese findet sich nur versteckt auf der Comparis-Seite in einem unscheinbaren Nachtrag zur Umfrage: «Sie ist nicht repräsentativ.» [1]

Alles andere wäre auch erstaunlich gewesen, zeigen doch die Zahlen repräsentativer Umfragen ein anderes Bild: Der Bevölkerungsanteil, der die Krankenkassenprämien als Problem bezeichnet, ist 2017 auf den tiefsten Stand der letzten 15 Jahre gesunken [2-3]. Der Anteil, der Arzt- und Medikamentenkosten als Problem

Der Bevölkerungsanteil, der die Krankenkassenprämien als Problem bezeichnet, ist auf den tiefsten Stand seit 15 Jahren gesunken.

wahrnimmt, hat sich im letzten Jahr sogar nahezu halbiert [2]. Zwar empfindet auch aktuell jeder Dritte die Prämien als Problem [2], was zwingend Lösungen erfordert. Es gilt aber auch den Kontext im Auge zu behalten: Ebenfalls ein Drittel [2], in anderen Umfragen sogar die Hälfte der Bevölkerung [4], bezeichnet die Steuerlast als starke finanzielle Belastung. Dennoch werden Kostendeckel ausschliesslich für - mitunter lebenswichtige - Gesundheitsleistungen diskutiert, aber nicht z.B. für die öffentliche Verwaltung. Den Präferenzen der Bevölkerung entspricht dies nicht: Dürfte sie die Staatsausgaben umverteilen, würde z.B. das Budget für die öffentliche Verwaltung um $24 \%$ reduziert - die Gesundheitsausgaben würde die Bevölkerung hingegen um 8 Prozent erhöhen [4]. Letzteres ist konsequent, wenn man bedenkt, dass die Mehrheit der Bevölkerung ausnahmslos für alle Bereiche der Gesundheitsversorgung mindestens genauso viel Geld wie bisher aufwenden möchte und auch Rationierungen sehr teurer Behandlungen klar ablehnt, sei es durch das Bundesgericht (65\%), das BAG (76\%) oder die Krankenkassen (78\%) [3].
Die Bevölkerung legt dennoch keine undifferenzierte Konsumhaltung an den Tag: Die Mehrheit erkennt die Notwendigkeit eines stärkeren Kostenbewusstseins an, wie sich an der wachsenden Zustimmung zur Erhöhung der minimalen (53\%) und der maximalen (58\%) Franchise ablesen lässt [2]. Und auch das Problem der Lastenverteilung wird in der Bevölkerung anerkannt, wie die Mehrheiten für Kinder-Prämienbefreiungen insbesondere für einkommensschwache Haushalte und die Entlastung junger Erwachsener zeigen [2].

Doch nicht nur solche punktuellen Massnahmen könnten Kostenbewusstsein und Eigenverantwortung fördern, die Lastenverteilung verbessern und den Prämienzahler entlasten. Die drängendste Aufgabe der Gesundheitspolitik wäre, die einheitliche Finanzierung ambulanter und stationärer Leistungen voranzutreiben. Sonst wird die Verlagerung von Behandlungen aus dem - überwiegend kantonal finanzierten - stationären Bereich in die - ausschliesslich prämienfinanzierte - ambulante Versorgung die Versicherten immer stärker belasten. Allein diese Korrektur der heute finanzierungsbedingten Fehlanreize birgt diversen Berechnungen zufolge ein grosses Sparpotenzial - ohne Rationierung und Qualitätsverlust [5].

\section{Dürfte die Bevölkerung die Staatsausgaben} umverteilen, würde sie die Gesundheitsausgaben um 8 Prozent erhöhen.

Würden gute Nachrichten genauso nachgefragt wie Skandalisierungen, hätte die 20 Minuten Schlagzeile auch lauten können «Prämienentwicklung bereitet immer weniger Menschen Sorge»: Statt noch $63 \%$ in 2003 zählten 2016 nur noch 21\% die Krankenkassenprämien zu den fünf wichtigsten Sorgen der Schweiz [6]. Auch «Vier von fünf Personen beurteilen die Entwicklung des Gesundheitswesens als positiv» wäre eine korrekte Information gewesen - interessant auch, dass sich dieser Anteil seit 2003 von $47 \%$ auf $81 \%$ erhöht hat [3]. Zweifelsohne müssen wir Probleme lösen und Verbesserungen vorantreiben - Panikmache ist jedoch kein guter Ratgeber! 